Brit. J. industr. Med., 1961, 18, 165.

\title{
THE EFFECT OF FILM QUALITY ON READING RADIOGRAPHS OF SIMPLE PNEUMOCONIOSIS IN A TRIAL OF $X$-RAY SETS
}

BY

\author{
F. D. K. LIDDELL \\ From the Medical Statistics Branch, National Coal Board, London
}

(RECEIVED FOR PUBLICATION FEBRUARY 20, 1961)

Four chest radiographs $(14$ in. $\times 14$ in. postero-anterior) for each of 86 coal-miners were taken (in a trial to compare $x$-ray sets) and assessed by a number of experienced readers for both quality and pneumoconiosis. All films were developed by one technician under standard conditions so that variations in the quality of the films produced for one subject arose because of differences in the sets and in the way they were used by the radiographers taking the films. The data thus obtained allowed a study of film quality to be made (a) in relation to the subject and (b) as it affected the reading of simple pneumoconiosis.

The subjects were selected to include a high proportion whose earlier radiographs showed pneumoconiosis; they were thus substantially older than a normal colliery population.

The assessments of quality were found to be reasonably consistent both between observers and on different occasions for the same observer.

A clear tendency was found for the quality of a film to depend on the subject. Men with no radiological evidence of pneumoconiosis tended to produce films which were assessed as of better quality than those of men with pneumoconiosis, however slight. Among the latter, chest thickness had an important effect on film quality; men with thicker chests produced poorer films. The subject's age did not appear to have any effect on the quality of his film.

Film quality was found to introduce only slight biases into the reading of pneumoconiosis. Individual readers varied considerably so that, although on average the readers tended to overcorrect for technical faults, i.e. to read more abnormality in black films than in good ones, and less in grey, some readers undercorrected slightly.

What little evidence was available did not suggest that poor quality of films introduced any excess variability into film reading.

In 1956 the National Coal Board approved a scheme for the periodic radiographic examination of all mineworkers, to provide a biological check on the effectiveness of dust suppression in the industry, to help to eradicate tuberculosis and, of course, to offer a diagnostic $x$-ray service. Nine mobile $x$-ray units were required and a trial was held to discover which of four $x$-ray sets* produced the best films.

During the trial 86 miners at one colliery in Kent had radiographs taken on the four sets each within

* Preliminary discussion with manufacturers and examination of tenders had revealed that only three manufacturers could supply and maintain appropriate equipment. Each provided for the trial one maintain appropriate equipment. Each provided for the trial one
apparatus (W, XI, and $\mathrm{Y}$ ) using one particular form of automatic apparatus (W, XI, and $Y$ ) using one particular form of automatic control and his apparatus using the second form of control (X2) was the fourth set in the trial. a few minutes. A number of experienced readers assessed the quality of each film and read them all for pneumoconiosis. The object of the trial was achieved by scoring each assessment of quality on a simple scale and by totalling the scores for the films produced on each set.

The data available allowed an examination to be made of the way in which the quality of a film is related to the subject and of the effects of film quality on the reading of pneumoconiosis. This paper discusses these examinations, after describing the trial briefly.

\section{Description of the Trial}

The main intention of the trial was to compare chest $x$-ray films $(14$ in. $\times 14$ in. postero-anterior) 
TABLE 1

AGE AND PREVIOUS RADIOLOGICAL CATEGORY OF SUBJECTS

\begin{tabular}{|c|c|c|c|c|c|c|c|}
\hline \multirow{2}{*}{$\begin{array}{c}\text { Two Readings of } \\
\text { Radiological Category } \\
\text { of } 1955 \text { Film }\end{array}$} & \multicolumn{6}{|c|}{ Age (Years) } & \multirow{2}{*}{ Total } \\
\hline & Up to 19 & 20 to 29 & 30 to 39 & 40 to 49 & 50 to 59 & 60 and Over & \\
\hline $\begin{array}{c}0,0 \\
0,1 \\
1,1 \\
1,2 \\
2,2 \\
2,3 \\
3,3 \\
\text { PMF, PMF }\end{array}$ & $\begin{array}{l}\underline{3} \\
\underline{\equiv} \\
\underline{\equiv}\end{array}$ & $\begin{array}{l}\frac{4}{1} \\
\text { 三 } \\
\text { 三 }\end{array}$ & $\begin{array}{l}\frac{6}{3} \\
1 \\
\frac{1}{2} \\
=\end{array}$ & $\begin{array}{l}4 \\
7 \\
3 \\
3 \\
5 \\
1 \\
1\end{array}$ & $\begin{array}{l}4 \\
4 \\
4 \\
2 \\
4 \\
3 \\
4 \\
4\end{array}$ & $\begin{array}{l}4 \\
4 \\
1 \\
2 \\
1 \\
2 \\
-\end{array}$ & $\begin{array}{r}25 \\
19 \\
8 \\
8 \\
11 \\
4 \\
6 \\
5\end{array}$ \\
\hline Total & 3 & 5 & 11 & 24 & 29 & 14 & 86 \\
\hline
\end{tabular}

of approximately 100 working miners taken on each apparatus under review. Conditions were to be as close as possible to those under which the nine mobile $x$-ray units would be operating; each manufacturer was to nominate a radiographer to operate that firm's own equipment; the films were to be handled and developed in one darkroom by one National Coal Board technician using an automatic processing unit so that conditions were kept as nearly identical as possible, particularly while all the films for one subject were being processed; the assessment would be by four experts nominated by a Board Sub-committee. $\dagger$

Nearly 1,400 men had been $x$-rayed at Chislet colliery in Kent in June 1955 and the films taken then, together with the readings by one observer on two separate occasions, were available. The men's ages were also known.

The subjects were chosen from the men known to be still employed at Chislet, to include a high proportion with evidence of pneumoconiosis and particularly of those whose films had been read differently on the two occasions.

The trial was carried out at Chislet in June 1957. The co-operation of the men was excellent and out of 100 selected all but 13 attended. One film was blank and all films of that subject have been excluded from this study. The ages and previous radiological categories of the remaining 86 subjects are given in Table 1. It must be remembered that the sample was not representative of a colliery population in that the proportion of men whose 1955 films were read as normal, or with little radiological evidence of pneumoconiosis, was deliberately reduced very greatly. Since the men with more advanced categories of pneumoconiosis tend to be the older men in the colliery, the sample contains a much higher proportion of older men than is representative.

Each man was allocated an appointment in

†Later, assessments were made by a number of other readers. random order and in only four cases was the order changed; the essential randomness was unaffected. Each man was examined on all four types of equipment in quick succession and so there were 344 films in all in the trial.

Every effort was made to ensure uniform conditions; details are given in the Appendix. The use of only one darkroom and the same technician throughout made it most probable that all films were subjected to similar conditions of handling.

Before each man had a radiograph taken, his chest thickness was measured (in $\mathrm{cm}$.) at maximum inspiration at the nipple level, by one observer. It is more usual to measure chest thickness during quiet respiration and the values of this paper are, therefore, larger than usually reported in papers on radiographic technique.

It was, unfortunately, impracticable in this investigation to assess the effect of chest thickness on the 1955 films in the same way as those taken in this trial in 1957.

After the trial was completed each film was allocated a reading number in a new order which ensured that no two successive films were of the same man and that the films taken on any particular set of equipment were distributed quasi-randomly throughout the series.

Each assessor read each film independently, with all identifying marks obscured, under identical viewing conditions. He recorded for each film an assessment of its quality from the point of view of reading pneumoconiosis, scoring on the following basis:

+1: Highly acceptable, above average, very good or technically desirable.

0: Average, acceptable, technically reasonable.

-1: Below average, poor, unacceptable.

Each reader also recorded his reading of pneumoconiosis using the I.L.O. 1950 classification.

Two readers, A and B (a senior member of the Medical Research Council's Pneumoconiosis 
Research Unit and the Medical Officer in charge of one of the Board's Research $x$-ray units), read the films on two separate occasions each. Four other readers, $\mathrm{C}, \mathrm{D}, \mathrm{E}$, and $\mathrm{F}$ (another senior member of the P.R.U., a full-time experienced member of a Pneumoconiosis Medical Panel of the Ministry of Pensions and National Insurance, a consultant in industrial medicine with particular interest in and experience of chest diseases, and a clinician with previous experience of pneumoconiosis but who had not been reading radiographs for some time before the trial), read them on one occasion each. (The order in which the readers' experience is described does not necessarily correspond to the order of their code letters.)

\section{Consistency in Assessment of Quality}

The assessments of quality are summarized in Table 2. It is clear that, although there were differences between the readers in the general level of assessment, each reader placed sets $\mathrm{X} 2$ and $\mathrm{X} 1$ above sets $W$ and $Y$, although there was a certain amount of interchange between $X 1$ and $X 2$ and between $W$ and $Y$; there was no observer who placed either $\mathrm{Y}$ or $\mathrm{W}$ above either X2 or X1. It is of interest that exactly similar rankings were obtained when the films were assessed for quality by a further eight readers, including representatives of two of the manufacturers. The consistency with which sets X1 and $\mathrm{X} 2$ were placed highest justified their preference and, as they differed only in their methods of exposure control, the scoring, despite its apparent crudity, achieved its primary purpose. It is, of course, possible that the results were influenced either by the ancillary equipment which each manufacturer provided for his own set in this field trial or by the degree of success with which each radiographer handled his own firm's set. The reasons for the comparative failure of sets $\mathrm{W}$ and $\mathrm{Y}$ are not important since the trial was intended to assess overall performance in the field. In any case, the concern of this paper is only that there were available, for each subject, four films usually of varying quality.

The two observers who read the films twice gave about three-quarters of the films the same assessment of quality on the two occasions. In no case did either of these readers assess a film as good $(+1)$ on one occasion and bad $(-1)$ on another.

The most noticeable difference between the standards of the observers was that Reader $\mathrm{C}$ never gave a score of +1 . Excluding this reader, there were seven readings of quality for each of the 344 films and all seven readings were in agreement for 87 (i.e. just over a quarter) of the films. There were only eight films where one observer gave an assessment of +1 and another an assessment of -1 ; no explanation for these discrepancies can be given.

\section{The Data}

For each of the 344 films there were thus eight assessments of quality $(+1,0$ or -1$)$ and eight readings of pneumoconiosis $(0,1,2,3$, or P.M.F.). A "Quality Score" was obtained for each film by adding together the eight individual assessments. This procedure is not strictly justifiable (on statistical grounds) but because of the relative consistency of the assessors, it does provide fairly reliable differentiation between films, in terms of quality. A film which every assessor thought good would have a "Quality Score" of +8 ; one which every assessor thought bad, -8 .

TABLE 2

SUMMARY OF ASSESSMENTS OF FILM QUALITY

\begin{tabular}{|c|c|c|c|c|c|c|c|c|c|c|c|c|c|c|c|c|}
\hline \multirow{3}{*}{ Set } & \multicolumn{4}{|c|}{$\begin{array}{c}\text { Reader A: } \\
\text { 1st Occasion }\end{array}$} & \multicolumn{4}{|c|}{$\begin{array}{c}\text { Reader A: } \\
\text { 2nd Occasion }\end{array}$} & \multicolumn{4}{|c|}{$\begin{array}{l}\text { Reader B: } \\
\text { 1 st Occasion }\end{array}$} & \multicolumn{4}{|c|}{$\begin{array}{c}\text { Reader B: } \\
\text { 2nd Occasion }\end{array}$} \\
\hline & \multicolumn{3}{|c|}{ Scores } & \multirow{2}{*}{$\begin{array}{l}\text { Total } \\
\text { Score }\end{array}$} & \multicolumn{3}{|c|}{ Scores } & \multirow{2}{*}{$\begin{array}{l}\text { Total } \\
\text { Score }\end{array}$} & \multicolumn{3}{|c|}{ Scores } & \multirow{2}{*}{$\begin{array}{l}\text { Total } \\
\text { Score }\end{array}$} & \multicolumn{3}{|c|}{ Scores } & \multirow{2}{*}{$\begin{array}{l}\text { Total } \\
\text { Score }\end{array}$} \\
\hline & -1 & 0 & +1 & & -1 & 0 & +1 & & -1 & 0 & +1 & & -1 & $\mathbf{0}$ & +1 & \\
\hline \multirow[t]{4}{*}{$\begin{array}{l}\mathbf{X} 2 \\
\mathbf{X} 1 \\
\mathbf{W} \\
\mathbf{Y}\end{array}$} & $\begin{array}{l}16 \\
11 \\
22 \\
34\end{array}$ & $\begin{array}{l}35 \\
55 \\
52 \\
46\end{array}$ & $\begin{array}{r}35 \\
20 \\
12 \\
6\end{array}$ & $\begin{array}{r}+19 \\
+9 \\
-10 \\
-28\end{array}$ & $\begin{array}{r}15 \\
9 \\
14 \\
29\end{array}$ & $\begin{array}{l}35 \\
50 \\
59 \\
50\end{array}$ & $\begin{array}{r}36 \\
27 \\
13 \\
7\end{array}$ & $\begin{array}{r}+21 \\
+18 \\
-1 \\
-22\end{array}$ & $\begin{array}{l}11 \\
13 \\
30 \\
33\end{array}$ & $\begin{array}{l}48 \\
53 \\
52 \\
52\end{array}$ & $\begin{array}{r}27 \\
20 \\
4 \\
1\end{array}$ & $\begin{array}{r}+16 \\
+7 \\
-26 \\
-32\end{array}$ & $\begin{array}{l}15 \\
12 \\
33 \\
40\end{array}$ & $\begin{array}{l}45 \\
54 \\
50 \\
44\end{array}$ & $\begin{array}{r}26 \\
20 \\
3 \\
2\end{array}$ & $\begin{array}{r}+11 \\
+8 \\
-30 \\
-38\end{array}$ \\
\hline & \multicolumn{4}{|c|}{ Reader C } & \multicolumn{4}{|c|}{ Reader D } & \multicolumn{4}{|c|}{ Reader E } & \multicolumn{4}{|c|}{ Reader F } \\
\hline & \multicolumn{3}{|c|}{ Scores } & & \multicolumn{3}{|c|}{ Scores } & & \multicolumn{3}{|c|}{ Scores } & & \multicolumn{3}{|c|}{ Scores } & \\
\hline & -1 & 0 & +1 & Score & -1 & 0 & +1 & Score & -1 & 0 & +1 & Score & -1 & 0 & +1 & Score \\
\hline $\begin{array}{l}\mathbf{X} 2 \\
\mathbf{X} 1 \\
\mathbf{W} \\
\mathbf{Y}\end{array}$ & $\begin{array}{l}33 \\
33 \\
68 \\
62\end{array}$ & $\begin{array}{l}53 \\
53 \\
18 \\
24\end{array}$ & $\begin{array}{l}\mathbf{0} \\
0 \\
0 \\
0\end{array}$ & $\begin{array}{l}-33 \\
-33 \\
-68 \\
-62\end{array}$ & $\begin{array}{l}16 \\
11 \\
32 \\
34\end{array}$ & $\begin{array}{l}59 \\
63 \\
53 \\
51\end{array}$ & $\begin{array}{r}11 \\
12 \\
1 \\
1\end{array}$ & $\begin{array}{r}-5 \\
+1 \\
-31 \\
-33\end{array}$ & $\begin{array}{r}17 \\
7 \\
25 \\
24\end{array}$ & $\begin{array}{l}64 \\
75 \\
60 \\
61\end{array}$ & $\begin{array}{l}5 \\
4 \\
1 \\
1\end{array}$ & $\begin{array}{r}-12 \\
-3 \\
-24 \\
-23\end{array}$ & $\begin{array}{l}15 \\
11 \\
20 \\
30\end{array}$ & $\begin{array}{l}58 \\
58 \\
51 \\
49\end{array}$ & $\begin{array}{r}13 \\
17 \\
15 \\
7\end{array}$ & $\begin{array}{r}-2 \\
+6 \\
-5 \\
-23\end{array}$ \\
\hline
\end{tabular}


TABLE 3

DISTRIBUTION OF FILMS BY "QUALITY SCORE"

\begin{tabular}{|c|c|c|c|}
\hline $\begin{array}{c}\text { "Quality Score" } \\
\text { (Total of Eight } \\
\text { Readings) }\end{array}$ & \multicolumn{2}{|c|}{ Number of Films } & Classification \\
\hline $\begin{array}{l}+8 \\
+7 \\
+6 \\
+5\end{array}$ & $\begin{array}{r}0 \\
2 \\
6 \\
12\end{array}$ & \multirow{3}{*}{154} & \multirow{3}{*}{ "Acceptable"* } \\
\hline $\begin{array}{l}+4 \\
+3 \\
+2 \\
+1\end{array}$ & $\begin{array}{l}16 \\
19 \\
23 \\
25\end{array}$ & & \\
\hline 0 & 51 & & \\
\hline $\begin{array}{l}-1 \\
-2 \\
=3 \\
-4\end{array}$ & $\begin{array}{l}47 \\
31 \\
21 \\
15\end{array}$ & \multirow{2}{*}{190} & \multirow{2}{*}{ "Poor" } \\
\hline $\begin{array}{l}-5 \\
-6 \\
=7 \\
-8\end{array}$ & $\begin{array}{l}19 \\
17 \\
19 \\
21\end{array}$ & & \\
\hline All & \multicolumn{2}{|l|}{344} & - \\
\hline
\end{tabular}

*For definition of "Acceptable" and "Poor" see text. This Table should not be taken to mean that more than half the films were unacceptable to all readers.

TABLE 4

DISTRIBUTION OF SUBJECTS BY "PNEUMOCONIOSIS SCORE'"

\begin{tabular}{c|l|c}
\hline $\begin{array}{c}\text { "Pneumoconiosis Score" } \\
\text { (Total of 32 Readings) }\end{array}$ & Group Title & $\begin{array}{c}\text { Number } \\
\text { of Subjects }\end{array}$ \\
\hline 0 & "Pure normal" & 13 \\
9 to 8 & "Lower O"” & 20 \\
17 to 48 & "Upper O" & 9 \\
49 to 80 & "1" & 16 \\
81 to 96 & "2", & 11 \\
Any one reading of P.M.F. & "P.M.F." & 13 \\
\hline All & - & $85^{*}$ \\
\hline
\end{tabular}

*Excluding the one subject all of whose films were unreadable.

TABLE 5

DISTRIBUTION OF SUBJECTS ACCORDING TO THE NUMBERS OF "ACCEPTABLE" AND "POOR" FILMS

\begin{tabular}{l|c|c}
\hline & \multicolumn{2}{|c}{ Number of Subjects } \\
\cline { 2 - 3 } & Observed & Expected \\
\hline All four films “Acceptable" & 14 & 3.45 \\
Three films "Acceptable", one "Poor" & 13 & 17.05 \\
Two films "Acceptable", two "Poor" & 16 & 31.55 \\
One film "Acceptable", three "PPoor" & 27 & 25.94 \\
No films "Acceptable", all four "Poor" & 16 & 8.00 \\
\hline Total & \multicolumn{2}{|c|}{86} \\
\hline
\end{tabular}

The distribution of the films by "Quality Score" is given in Table 3 , where it can be seen that roughly half the films had "Quality Scores" of 0 or better and these we defined as "Acceptable"; roughly half the films had scores of -1 or worse and these we defined as "Poor".

Similarly, a "Pneumoconiosis Score" was obtained for each subject by adding together the 32 readings (eight each for four films) for each subject,* unless any of the 32 readings was of P.M.F., in which case the subject was allocated to a "P.M.F." group. A "Pneumoconiosis Score" of O means that all 32 readings were normal; a "Pneumoconiosis Score" of 48 could mean that half the readings were category 1 and the other half category 2 so that the man's condition probably lies close to the borderline between these two categories. For a small number of subjects, a few readings were not available because particular observers had considered individual films "unreadable". Allowance has been made for these missing values to obtain an approximate "Pneumoconiosis Score". The distribution of the subjects by this measure is given in Table 4 ; in no case is the classification indicated in this Table likely to have been affected by "unreadable" films.

\section{Consistency of Differences in Quality between Subjects}

For each subject there are four films classifiable as "Acceptable" or "Poor". Table 5 gives the distribution of the 86 subjects according to the number of their films in these two classes. This Table also gives the expected distribution of the subjects on the assumption that the chance of any one film being classed as "Acceptable" or "Poor" is independent of the classification of any other film of the same subject. There is a clear tendency for many more subjects than expected to produce either four "Acceptable" films or four "Poor" films. This result is highly significant statistically: $\chi^{2}=$ 48.93, with 3 degrees of freedom; $p<<0.001$. Thus we conclude that the quality of a film depends to a considerable extent on the subject.

\section{Factors Affecting Film Quality}

We examined the relationship between film quality and the subject's age and chest thickness, for each pneumoconiosis group separately. In Table 6 we give for each group the average age, the average chest thickness, and the average "Quality Score". It is clear from this Table that the "Pure Normal" group differed markedly from those with evidence of pneumoconiosis, in that, on average, they were much younger, had thinner chests and considerably higher "Quality Scores". Amongst those with evidence of pneumoconiosis there was only a slight tendency for the men with more pneumoconiosis to be older than those with little

*Again this procedure is not strictly justifiable but it does provide fairly reliable differentiation between subjects, in terms of pneumoconiosis. An analogous procedure was used by Rivers, Wise, King, and Nagelschmidt (1960) who used a different scale of pneumoconiosis which should not be confused with the present "Pneumoconiosis Score" or the group titles defined in Table 4. 
pneumoconiosis. There was no clear tendency for either chest thickness or "Quality Score" to be related to pneumoconiosis.

Within each pneumoconiosis group, we found a relationship between a subject's chest thickness and the average "Quality Score" of his four films. For men in the "Pure Normal" group the relationship was very slight. In the various groups of men with evidence of pneumoconiosis the relationships were similar: the average "Quality Score" decreased markedly with increasing chest thickness. One subject, excluded from these results because all of his films were assessed as "unreadable" by all readers, had a chest thickness of $32 \mathrm{~cm}$., i.e. $3 \mathrm{~cm}$. greater than any other subject. The results are presented in Fig. 1. It can be seen that the films for men in the "Pure Normal" group were generally assessed as better than for the men in the other groups, even when allowance has been made for chest thickness. There was no evidence from this examination that the age of the subject had any effect on the quality of his films.

Within each of the seven groups of subjects according to "Pneumoconiosis Score", the "Quality Scores" were related to the age and chest thickness of the subjects, for the films taken on each $x$-ray set separately. No association could be found with the age of the subject, but there was a general tendency for the "Quality Score" to decrease with increasing chest thickness. The effects differed from one group to another and for the different $x$-ray sets: they were hardly existent for the "Pure Normal" group; they were slightly more marked in the other groups for sets $\mathrm{X} 1$ and $\mathrm{X} 2$ than for sets W and Y. In general, the "Quality Scores" on sets $\mathrm{X} 1$ and X2 were markedly higher for men with comparatively thin chests, than those on sets $\mathrm{W}$ and Y, but for men with thick chests there was little difference in the quality of films from all four sets. For men in the "Pure Normal" group the assessment of quality was generally higher than for the other groups, when age and chest thickness had been allowed for. The results are presented diagrammatically in Fig. 2.
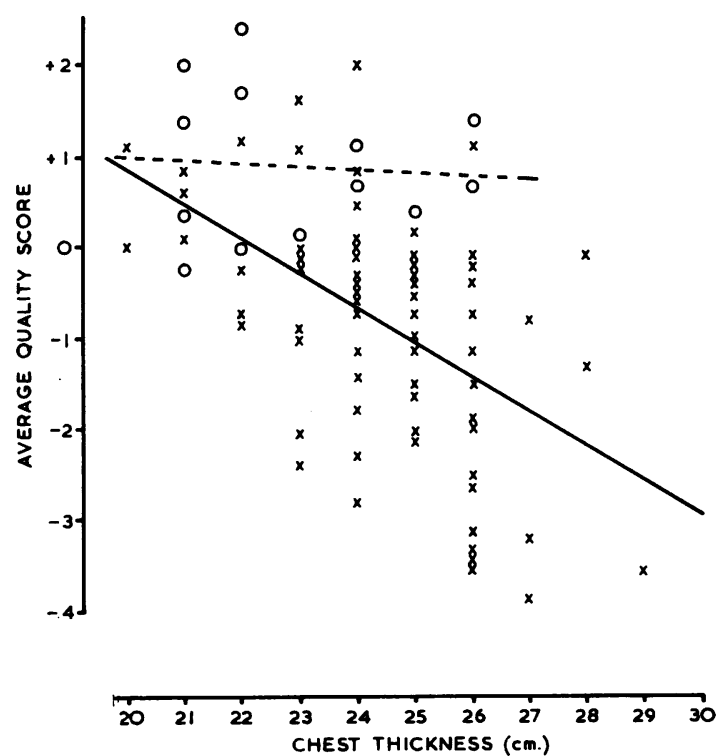

FIG. 1.-Chest thickness and film quality.

O Subjects in "Pure Normal" group - - - -

X Other subjects

\section{Factors Affecting Reading Error}

Although Rivers et al. (1960) demonstrated an association between radiological category of simple pneumoconiosis and dust in the lung, it was by no means perfect. This is not unexpected because, as pointed out by Gilson (1960), the reading of a chest film is a descriptive process in that the classification of radiographs was originally developed on an empirical basis to provide a semi-quantitative scale of increasing abnormality. Indeed, any particular reading of a film is liable to variation from three causes. First, the film does not show the particles of dust themselves but only the opacities attributed to their retention in the lung; it may therefore be affected by the type of dust, by its distribution within the lung and by the radiological characteristics of the lung itself. Secondly, there is an element of observer error in assessing the number and size

TABLE 6

AVERAGE AGES, CHEST THICKNESSES, AND FILM “OUALITY SCORES" OF SUBJECTS IN PNEUMOCONIOSIS GROUPS

\begin{tabular}{|c|c|c|c|c|}
\hline Pneumoconiosis Group & Number of Subjects & $\begin{array}{l}\text { Average Age of Subjects } \\
\text { (years) }\end{array}$ & $\begin{array}{c}\text { Average Chest Thickness } \\
\text { of Subjects } \\
\text { (cm.) }\end{array}$ & $\begin{array}{c}\text { Average "Quality Score" } \\
\text { of Films of } \\
\text { Subjects }\end{array}$ \\
\hline $\begin{array}{l}\text { "Pure normal” } \\
\text { "Lower O”" } \\
\text { “Upper O"” } \\
\text { “1"” } \\
\text { “2 and 3"” } \\
\text { “P.M.F." }\end{array}$ & $\begin{array}{r}13 \\
20 \\
9 \\
16 \\
14 \\
13\end{array}$ & $\begin{array}{l}34 \cdot 5 \\
45 \cdot 4 \\
54 \cdot 0 \\
48 \cdot 8 \\
48 \cdot 9 \\
54 \cdot 8\end{array}$ & $\begin{array}{l}22 \cdot 9 \\
24 \cdot 4 \\
24 \cdot 8 \\
24 \cdot 7 \\
23 \cdot 9 \\
24 \cdot 5\end{array}$ & $\begin{array}{l}+1.9 \\
-1.1 \\
-2.2 \\
-1.9 \\
-1.7 \\
-2.1\end{array}$ \\
\hline
\end{tabular}



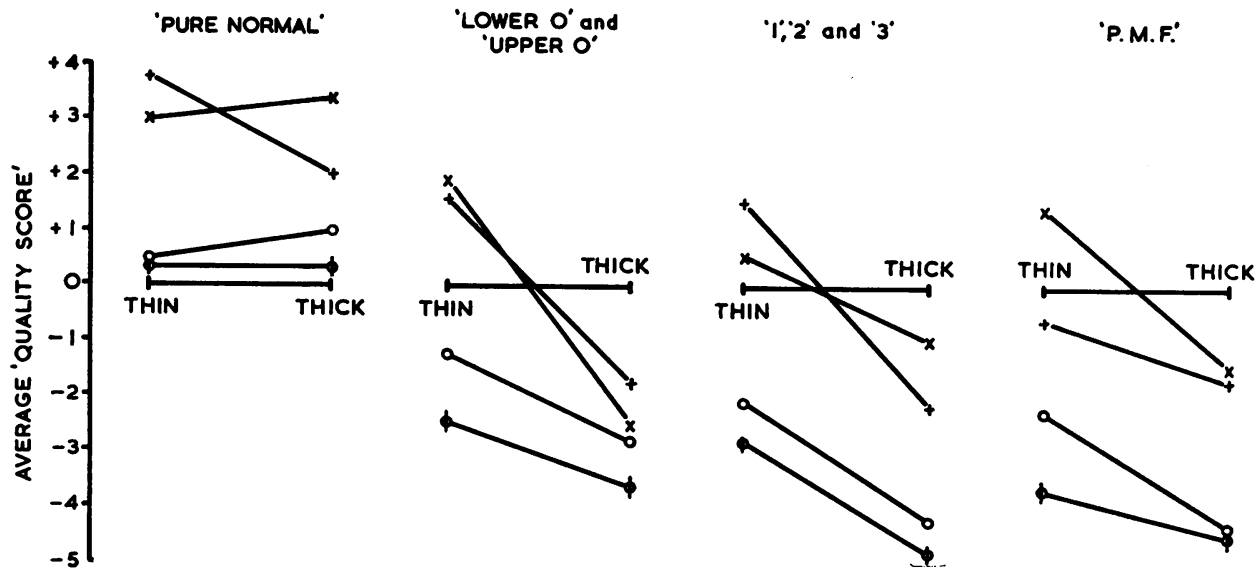

FIG. 2.-The relationship of film quality and $x$-ray set, chest thickness, and pneumoconiosis. "Thin" = up to $24 \mathrm{~cm}$. chest thickness; "Thick" $=25 \mathrm{~cm}$. or more chest thickness. $X$ set X2 + set X1 $\mathrm{O}$ set $\mathrm{W} \quad \phi$ set $\mathrm{Y}$

of the opacities in a particular film. Thirdly, radiographic technique affects the appearance of a film; readers unfamiliar with pneumoconiosis tend to see less of it in over-exposed or over-penetrated (i.e. black) films and more in under-exposed or underpenetrated (i.e. grey) films, although, of course, experienced readers make allowances for these effects.

The "accuracy" of film reading has often been studied in terms of the consistency with which a number of readers assess a batch of films or of the consistency with which one reader assesses a batch of films on separate occasions. The classical work of Fletcher and Oldham (1949) embraced the examination of the effects of technique. For each of nine subjects, they had available three films: one of acceptable technique; one made deliberately too black; one deliberately too grey. They found a general tendency for less abnormality to be read in the black films and more in the grey films, although some of their readers had made adequate (or even in some cases too great) allowances for technique.

The present data made it possible to extend this approach and to examine how successful readers are in making corrections for technique in the ordinary course of reading. It is also possible to assess whether bad technique increases observer error. These topics are discussed in the following two sections in terms of the readings of the films of the subjects who produced at least one acceptable film and at least one poor film (see Table 5). Amongst the 56 such men were 10 for whom P.M.F. was read and these have all been excluded from the present studies.

\section{Effect of Film Quality on Reading Pneumoconiosis}

To assess the effect of technique on reading, we compared, for each subject, the reading of the film which had the lowest "Quality Score" for that subject with the reading of that subject's film which had the highest "Quality Score". To ensure a reasonably marked difference in quality, we excluded those subjects where the difference between the "Quality Scores" on the best and worst films was less than four. We also excluded two subjects because readings were not available since particular readers considered at least one film "unreadable". For the remaining 30 subjects, the film with the worst "Quality Score" was re-examined to determine the reason for the low assessment of its quality. In 14 cases the worst film was too black; in nine it was too grey; in the remaining seven it was assessed as worst because of such factors as movement or incomplete inspiration.

The results are given in Table 7; this is in three parts, according to the reason for the worst film being so assessed. In each part of the Table, we give, for each subject separately, the "Quality Score" on the best and worst films and, for each of these two films, the eight individual readings of the films. On the right of the Table we give the average of the readings on the best and worst films, together with the difference.

From Table $7 \mathrm{a}$, it can be seen that on average slightly more abnormality was read in films which were too black than in the best films of the same subject. The individual readers varied considerably; one had a general tendency to overread by about half a category on average whereas, at the other 
extreme, another reader underread by about one third of a category. Again the tendency is by no means common to every subject; the worst films for subjects 77 and 41 were read by the majority of readers as having more abnormality than the best films of the same subject; for most other subjects on the other hand the differences between the best and worst films tended to cancel out or were in any case infrequent.

From Table $7 \mathrm{~b}$, it can be seen that on average slightly less abnormality was read in the films which were too grey than in the best films of the same

TABLE 7a

READINGS ON BEST AND WORST FILMS: 14 SUBJECTS WHOSE WORST FILMS WERE BLACK

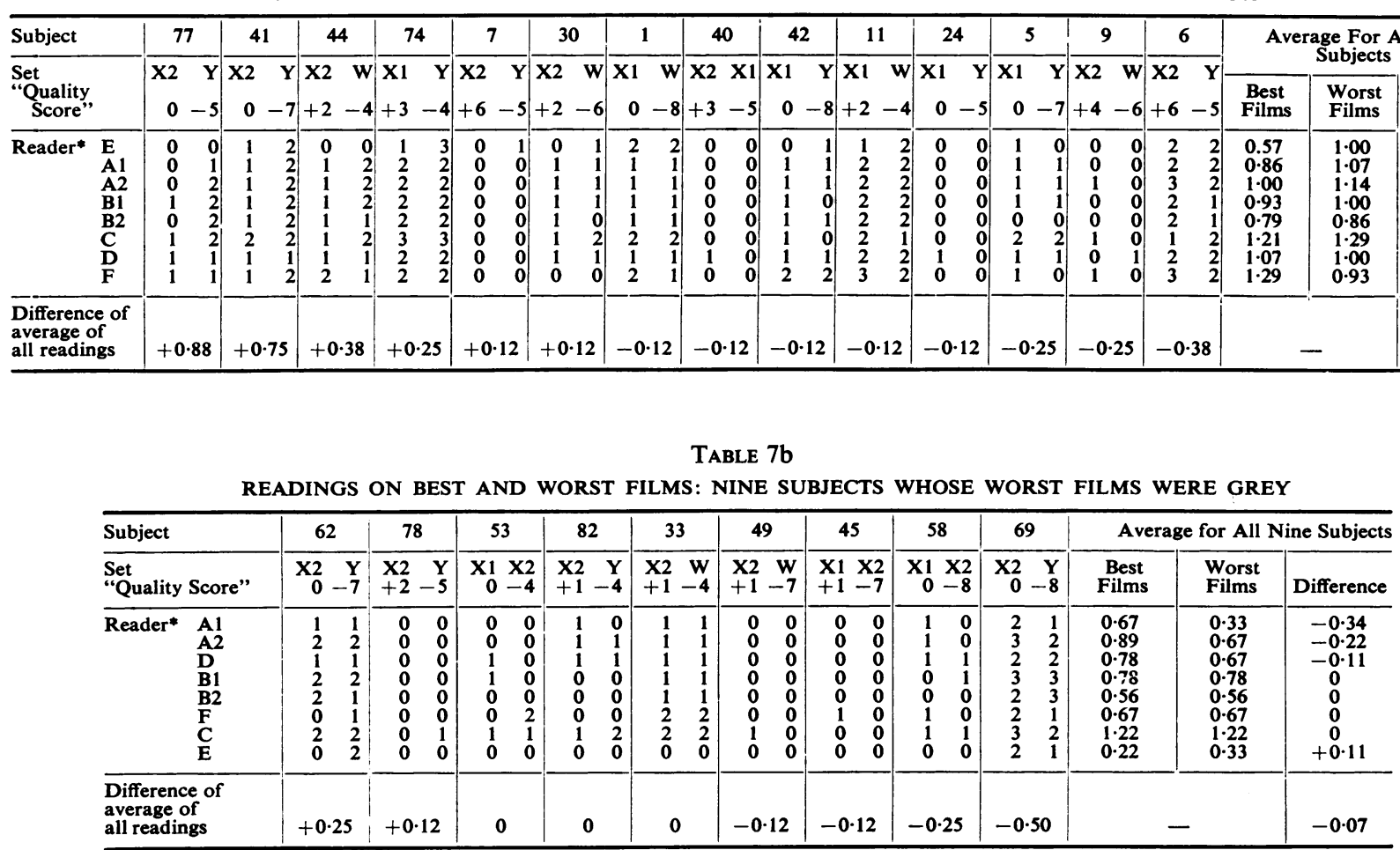

TABLE 7c

READINGS ON BEST AND WORST FILMS: SEVEN SUBJECTS WHOSE WORST FILMS WERE SO ASSESSED FOR OTHER REASONS

\begin{tabular}{|c|c|c|c|c|c|c|c|c|c|c|}
\hline \multirow{2}{*}{$\begin{array}{l}\text { Subject } \\
\text { Set } \\
\text { "Quality Score" }\end{array}$} & 37 & 80 & 64 & 29 & 52 & 34 & 28 & \multicolumn{3}{|c|}{ Average for All Seven Subjects } \\
\hline & $\begin{array}{lr}\text { X2 } & \text { W } \\
+2 & -3\end{array}$ & $\begin{array}{rr}X 2 & Y \\
+5 & -2\end{array}$ & $\begin{array}{rr}X 1 & Y \\
+4 & -1\end{array}$ & $\begin{array}{lr}X 2 & Y \\
+5 & -1\end{array}$ & $\begin{array}{ll}X 1 & X 2 \\
+2 & -2\end{array}$ & $\begin{array}{lr}X 2 & Y \\
+3 & -2\end{array}$ & $\begin{array}{ll}\text { X2 } & \text { W } \\
+5 & -3\end{array}$ & $\begin{array}{c}\text { Best } \\
\text { Films }\end{array}$ & $\begin{array}{l}\text { Worst } \\
\text { Films }\end{array}$ & Difference \\
\hline $\begin{array}{ll}\text { Reader* } & \text { C } \\
& \text { B1 } \\
& \text { F } \\
& \text { A2 } \\
& \text { E } \\
& \text { A1 } \\
& \text { B2 } \\
\text { D }\end{array}$ & $\begin{array}{ll}\mathbf{1} & \mathbf{2} \\
\mathbf{0} & \mathbf{1} \\
\mathbf{0} & \mathbf{2} \\
\mathbf{0} & \mathbf{1} \\
\mathbf{0} & \mathbf{0} \\
\mathbf{1} & \mathbf{1} \\
\mathbf{0} & \mathbf{0} \\
\mathbf{1} & \mathbf{1}\end{array}$ & $\begin{array}{l}1 \\
0 \\
0 \\
0 \\
0 \\
0 \\
0 \\
1\end{array}$ & $\begin{array}{l}2 \\
2 \\
2 \\
2 \\
1 \\
2 \\
2 \\
1\end{array}$ & $\begin{array}{l}0 \\
0 \\
0 \\
0 \\
0 \\
0 \\
0 \\
1\end{array}$ & $\begin{array}{l}0 \\
0 \\
1 \\
0 \\
0 \\
0 \\
0 \\
1\end{array}$ & $\begin{array}{l}1 \\
0 \\
1 \\
1 \\
0 \\
1 \\
0 \\
1\end{array}$ & $\begin{array}{l}\mathbf{3} \\
\mathbf{2} \\
\mathbf{3} \\
\mathbf{3} \\
\mathbf{3} \\
\mathbf{3} \\
\mathbf{3} \\
\mathbf{3}\end{array}$ & $\begin{array}{l}1.14 \\
0.57 \\
1.00 \\
0.86 \\
0.57 \\
1.00 \\
0.71 \\
1.29\end{array}$ & $\begin{array}{l}1.43 \\
0.86 \\
1.14 \\
1.00 \\
0.57 \\
0.86 \\
0.57 \\
0.86\end{array}$ & $\begin{array}{l}+0 \cdot 29 \\
+0 \cdot 29 \\
+0 \cdot 14 \\
+0 \cdot 14 \\
0 \\
-0 \cdot 14 \\
-0 \cdot 14 \\
-0 \cdot 43\end{array}$ \\
\hline $\begin{array}{l}\text { Difference of } \\
\text { average of } \\
\text { all readings }\end{array}$ & +0.62 & +0.12 & +0.12 & $\mathbf{0}$ & -0.12 & -0.25 & -0.38 & & & +0.01 \\
\hline
\end{tabular}

* For Readers $\mathbf{A}$ and $\mathbf{B}$, the digit indicates the occasion on which the films were read.

For each subject readings on the best films are on the left. 
subject. Again there were differences between readers and between subjects.

As might be expected, little pattern emerges from an examination of Table $7 c$.

\section{Efiect of Film Technique on Repeatability of Reading}

In the previous section we tried to discover whether film quality introduced a bias into readings. In this section we consider whether the reading of films of poor technique shows greater variation than the reading of films of good technique. We used two methods.

In the first method we compared the numbers of discrepancies in reading pairs of films of the same subject (a) when the films were both "Acceptable" (and their "Quality Scores" close together) and (b) when one film was "Acceptable" and the other "Poor" (and their "Quality Scores" were reasonably far apart). In Table 8 we list the 11 subjects whose films met the following criteria:

(i) At least two were "Acceptable" and at least one "Poor" film;

(ii) The "Quality Score" on the best film was at least four points greater than the "Quality Score" on the worst film;

(iii) The "Quality Score" on the second best film was within three points of the "Quality Score" on the best film.

A small number of subjects was excluded because two films had equal "Quality Scores".

In Table 8 we also indicate those readers whose readings for these 11 subjects differed (a) when reading the best and next best films and (b) when reading the best and worst films. An asterisk indicates that the difference was of two categories, otherwise all differences were of one category only. For five subjects there were more discrepancies when comparing best and worst films than when comparing best and next best films; for two subjects there were fewer discrepancies and for the remaining six subjects there were equal numbers. Similarly, two readers showed more differences between best and worst films than between best and next best films; with one reader this tendency was reversed but with the others there were no differences.

In the second method of comparison, we used the material of Table 7 for readers $A$ and $B$, both of whom read the films twice. One reader had slightly greater variability on the worst films than he had on the best, but for the other reader the tendency was reversed. In neither case was the difference in variability significant.

\section{Discussion}

It is not easy to quantify the results, especially as they related to six particular readers, whose general levels of reading pneumoconiosis differed considerably. However, for these six, differences in film quality appeared to introduce about the same lack of repeatability as did differences between readers with similar levels. In the extreme, the two readers whose levels differed most had many more disagreements with each other in their readings of the best films than each had, separately, between his readings of the best and worst films.

These findings are not obviously in line with those from the only other work on this subject known to the author: that of Fletcher and Oldham (1949) and that, as yet unpublished, of Wise (1959). However, comparison with either is difficult. Fletcher and Oldham only used nine subjects, and the variations in technique were deliberately introduced by altering the factors on one set. The changes produced may not be strictly comparable with the variations produced by the different sets in the present trial.

There is, however, one important difference that does seem valid. The earlier work showed that the errors were, on average, in the "expected" direction (i.e. more abnormality was read in grey films, less in 
black) whereas in the current study these tendencies were, if anything, reversed.

The material examined by Wise consisted of only one film for each subject. He assumed that the real distribution of abnormality (i.e. what ought to be read on perfect films) would be independent of film technique. The current study suggests that this assumption is not tenable.

Three further considerations must be borne in mind. First, the present sample of films was heavily biased by the exclusion of men without pneumoconiosis. Secondly, it was also biased by the inclusion of a high proportion of men whose earlier (1955) films had been read differently on two occasions by one experienced reader; difficulty in reading was thus not unexpected. Thirdly, since the films which were easiest to read were generally assessed as of good quality, there may be an important source of inaccuracy in the assessment of quality, which is clearly a subjective process.

\section{Conclusions}

(a) The quality of a film depends on the subject; in the circumstances of this trial, which simulated survey conditions, chest thickness but not age had an important effect on the average quality of the films.
Also those films showing pneumoconiosis were, for equal chest thickness, given a lower "quality" grading than those without pneumoconiosis.

(b) For those 30 subjects who had both good and bad films, film technique did not appear to introduce consistent biases into film reading nor any greater variability. In other words, the particular readers were in general able to make reasonable allowances for the effects of technique on the film's appearance.

(c) There are subjects, especially those with thick chests, in whom it is difficult to get technically good films, and it is in these that the effects of poor technique probably affect the accuracy of reading of pneumoconiosis most.

I should like to thank all those who took part in the trial and, in particular, Dr. J. C. Gilson. I owe a special debt of gratitude to Dr. P. J. Chapman, who conducted the trial and with whom I have had many very helpful discussions.

\section{REFERENCES}

Fletcher, C. M., and Oldham, P. D. (1949). Brit. J. industr. Med., 6, 168.

Gilson, J. C. (1960). Personal communication.

Rivers, D., Wise, M. E., King, E. J., and Nagelschmidt, G. (1960). Brit. J. industr. Med., 17, 87.

Wise, M. E. (1959). Personal communication.

\section{A P P E N D I X}

\section{Radiographic Details}

Before the trial was undertaken preliminary meetings were held with all the manufacturers where it was agreed that the target film distance would be standardized at 60 in. and that no added filtration (except that built into the tubes) would be used. It was also agreed that the maximum focal spot size would be $2 \mathrm{~mm}$., but all manufacturers used tubes with nominal focal spot sizes $1 \cdot 2$ $\mathrm{mm}$.

The tubes were all virtually new.

For use with the one method of exposure control, three cassettes were selected at random from amongst those belonging to the National Coal Board No. 2 Research $X$-ray Unit. A special type of cassette was necessary for use with the other method and such cassettes were provided by the manufacturer.

The intensifying screens, films, and chemicals were provided by the National Coal Board. High definition screens (as used by the N.C.B. Research $X$-ray Units) were provided and before the trial six pairs of screens were tested for comparability of speed and definition. The "speed" of the screen was compared using an aluminium step wedge and the definition compared using metal studding (threaded rod) of various sizes. Visual comparison showed no detectable difference between pairs of screens. Three pairs of screens, chosen at random, were mounted in the N.C.B. Research Unit's cassettes and the other three pairs of screens were mounted in the special cassettes for use with the second method of exposure control.*

The films used were 14 in. $\times 14$ in. Kodak Standard Series 6, all of one emulsion mix. Sheets of film were taken at random from each box of 75 films and tested for comparability using similar methods to those employed in testing the screens. The $x$-ray equipment used for these tests was that of the N.C.B.'s Unit (Siemens NeoHeliophos with four-valve full-wave rectification).

Darkroom, developing facilities, and chemicals were provided by the N.C.B. $X$-ray Unit. All films were handled and developed in the one darkroom by the same N.C.B. technician throughout. The developer used was Kodak DX.80, and the fixer Kodak $x$-ray fixer with hardener. Development time was standardized (five minutes at $68^{\circ} \mathrm{F}$.) for all films, using an automatic (Hills Russell) unit. A graphic record of the temperature of the developer was maintained by a recording thermograph, and showed that the temperature during each developing session was equal and constant. At no time did the temperature vary by more than $\pm 1^{\circ} \mathrm{F}$.

The developer was replenished at intervals, the amount

\footnotetext{
*See also last paragraph of this Appendix.
} 
added depending on the total area of exposed films processed (29 fl. oz., per 27 sq. ft.). In practice this means $29 \mathrm{fl}$. oz., for each 20 full-size radiographs developed.

The developing conditions throughout the trial were assessed by special test films. On each of these test strips, made from Kodak Standard Series $6 x$-ray film, there was a density step wedge prepared by exposure to a constant low wattage light source. The test films were processed at intervals and the densities on corresponding portions of different test films were measured with a Baldwin Vacuum Cell densitometer. By this means any gross variations in the developer likely to affect the finished $x$-ray films would be detected. Once testing was complete and the trial had started there was virtually no change in the shapes of the curves relating density to log exposure and no variation in the developer appears sufficient to affect the finished radiograph.

In addition to those men selected for the trial proper, 80 had radiographs taken by the N.C.B. $X$-ray Unit before the trial started and the exposed films were processed in the solutions to be used for the rest of the trial; thus the initial comparatively rapid changes in the developing solutions took place before the trial films were processed.
The details of radiographic techniques were left to the discretion of the individual operators within the broad limits that at least $300 \mathrm{~mA}$ should be employed and that the range of $\mathrm{kv}$ should be that conventionally used for full-size chest radiography.

To enable the radiographers in charge of the three $x$-ray sets to decide the details of their radiographic technique a selection was made of a further 20 men. (With the 100 men chosen for the trial proper and the $\mathbf{8 0}$ mentioned above, a total of 200 was involved in the trial.) These men, 10 of whom attended on each of two days, represented a range of age, chest thickness, and radiological appearances. Their $x$-ray films were handled and processed under the conditions of the trial.

When each man presented, he was identified and allotted a card containing an identifying number punched into a leaded strip. He was also allocated (in rotation) one cassette of each type. One of the N.C.B. research team escorted the man, ensuring that he was $x$-rayed on each set and that the number on the leaded card was entered, by $x$-radiation, on each of his films. The same cassette and thus the same pair of screens was used for all the one man's films taken with the exposure control common to those sets. Thus on each of the four sets, three cassettes were used in rotation. 